\title{
Women's experiences of endometriosis: a systematic review and synthesis of qualitative research
}

\author{
Kate Young, ${ }^{1}$ Jane Fisher, ${ }^{2}$ Maggie Kirkman ${ }^{3}$
}

\begin{abstract}
${ }^{1} \mathrm{PhD}$ Candidate, The Jean Hailes Research Unit, School of Public Health and Preventive Medicine, Monash University, Melbourne,

Australia

${ }^{2}$ Director, The Jean Hailes Research Unit, School of Public Health and Preventive Medicine, Monash University, Melbourne, Australia

${ }^{3}$ Senior Research Fellow, The Jean Hailes Research Unit, School of Public Health and Preventive Medicine, Monash University, Melbourne, Australia
\end{abstract}

\section{Correspondence to}

Ms Kate Young, The Jean Hailes Research Unit, Monash University, 6th Floor, Alfred Centre, 99 Commercial Road, Melbourne, VIC 3004, Australia; kate.young@monash.edu

Received 5 December 2013 Revised 23 March 2014 Accepted 3 July 2014 Published Online First 2 September 2014

\begin{abstract}
Background Endometriosis is experienced by approximately $10 \%$ of women worldwide; it is associated with significant burden on the woman, her family, and society.
\end{abstract}

Aim The aim of this systematic review was to synthesise the available qualitative literature to increase our understanding of the effects of endometriosis on women's lives.

Methods Seven social science and medical databases (PubMed, Medline, CINAHL, Web of Science, ScienceDirect, Psyclnfo and Embase) and Google Scholar were searched for peer-reviewed papers published in English of research using qualitative methods.

Results and conclusions Eighteen papers reporting 11 studies met the inclusion criteria. Participant numbers ranged from 15 to 61 women, all recruited from support groups and specialised clinics. Studies were conducted in high-income, Anglophone countries. The review identified four prominent themes: Life, Symptoms, Medical Experience, and Self. Women's reported experiences demonstrated opportunities for enhancing current clinical practice, including improved education about endometriosis for health professionals, the need to take a comprehensive approach to pain treatment, and initiating appropriate discussion of the impact on sex life. Significant evidence gaps were identified: there was inadequate investigation of women's experiences of endometriosis-associated infertility and of the impact of reduced social participation on perceived support and emotional well-being, and limited or no inclusion of the experiences of adolescent and post-menopausal women, women from low socioeconomic backgrounds, women who do not identify as Caucasian, and non-heterosexual women.

\section{BACKGROUND}

Endometriosis is an enigmatic, chronic and recurring disease affecting an estimated

\section{Key message points}

- Endometriosis has profound effects on women's lives.

- Further research is needed on the experience of endometriosis-related infertility and the impact of reduced social participation.

- Research needs to be inclusive of greater diversity among women.

1 in 10 women. ${ }^{1}$ It occurs when tissue similar to the endometrium, which normally lines the uterus, grows outside the uterus. This tissue implants in, and forms lesions on, other organs including the ovaries, bowel, bladder and the Pouch of Douglas. ${ }^{2}$ While the pathogenesis of the disease is not yet known, the retrograde menstruation theory has gained significant ground since it was first described in 1925. ${ }^{3}$ Diagnosis can be made definitively only upon visualisation at surgery. ${ }^{2}$ Common symptoms of endometriosis include painful menstruation, heavy menstrual bleeding, pain during intercourse, and infertility. There is little correlation between the physical extent of the disease and the severity of symptoms women report. $^{4}$ Common treatment options include progestogens, ovulation induction and surgery. However, these interventions can be associated with significant side effects and typically do not provide longterm relief. ${ }^{2}{ }^{5}$

While there is abundant literature on the scientific and medical aspects of endometriosis, the psychosocial impact of the condition has been the subject of little research. The resulting small body of literature has predominantly focused on the use of surveys featuring 
quality-of-life and pain scales. While such research is a valuable contribution to the literature, it does not provide evidence of women's experience of the disease and what it means to them. Research that uses qualitative methods, however, has the fundamental goal of understanding experience from the perspective of those who live with or through it.

Systematic reviews of qualitative research are particularly useful for summarising people's experiences with health care and may highlight areas of improvement that health policy and interventions could address. ${ }^{6}$ Because of the associated methodological and epistemological challenges, there is little consensus around the most appropriate method for systematically reviewing qualitative literature. Some argue that such reviews are not appropriate for this genre of research; however, as Britten ${ }^{7}$ stated: "The full contribution of qualitative research will not be realised if individual studies merely accumulate and some kind of synthesis is not carried out". It is only recently that the contribution made to knowledge by qualitative research has come to be recognised in medical journals. ${ }^{89}$ Further, qualitative research can be comparatively difficult to locate because search engines are equipped to identify quantitative research, not qualitative. ${ }^{10} \mathrm{~A}$ systematic review of women's experiences of endometriosis will provide insight into knowledge accumulated directly from women rather than from a clinical or physiological perspective.

There have been two previous systematic reviews of qualitative research examining women's experiences of endometriosis. Denny and Khan ${ }^{6}$ conducted the first with eight papers published between 1992 and 2004 and an undefined sample size. This was predominantly a methods paper and did not feature an in-depth discussion of the findings. According to these reviewers, the one constant theme reported in all studies was pain, which they dealt with briefly by presenting examples of women's descriptions of pain. The second review, by Culley et al., ${ }^{11}$ included 42 papers of which 23 reported research using quantitative methods, 16 qualitative and three mixed methods. The studies were conducted in high-income, Anglophone countries and Brazil. Participant numbers ranged from 23 to 1110 women in quantitative research, 13 to 61 women in qualitative research, and 30 to 465 women in mixed-methods research. The reviewers conducted a systematic thematic analysis the details of which are poorly described - across all papers. While synthesis of qualitative and quantitative literature can be useful, it must be conducted in such a way as to consider the different forms of knowledge yielded by the diverse epistemological positions and the implications of their contrasting meanings; this was not evident within this review. Further, multiple papers arising from a single study were not accounted for by appropriately weighting results.
The current review of research using qualitative methods was undertaken to bring the qualitative literature up to date using an appropriate synthesis method, with the aim of increasing our understanding of the effects of endometriosis on women's lives.

\section{METHODS}

A systematic review was conducted of the research using qualitative methods to investigate women's experiences of endometriosis.

\section{Inclusion and exclusion criteria}

The primary inclusion criterion was the use of qualitative research methods to investigate women's experiences of endometriosis. Papers must also have been published in English in peer-reviewed journals, include data only from women with surgicallydiagnosed endometriosis, and have sought accounts from women themselves (not from their partners, for example). Papers reporting the experiences of women with pelvic pain or suspected endometriosis were excluded.

\section{Search strategy and selection of papers}

Seven databases (PubMed, Medline, CINAHL, Web of Science, Science Direct, PsycInfo, Embase) and Google Scholar were individually searched using the term 'endometriosis' in conjunction with 'qualitative', 'interview', 'in-depth', 'focus group' or 'diary'. The references lists of located papers were searched to identify further potentially suitable papers.

The selection process is outlined in Figure 1. The titles and abstracts of papers initially located in the systematic search were examined to identify those apparently meeting the inclusion criteria. These papers were then read in full to assess their eligibility. Author KY conducted the initial search; authors KY and MK together made final decisions about inclusion.

\section{Assessment of quality}

There is no widely accepted tool with which to assess the quality of qualitative papers. It is difficult to apply standard quality assessment criteria to qualitative research which, by definition, reveals (and finds patterns in) complexity, diversity and change, rather than seeking the replicability and generalisability expected of quantitative research. ${ }^{12}$ The current review used broad quality assessment criteria to ensure inclusion only of studies using qualitative methods to privilege the experiential knowledge of women, thus addressing the primary research aim. In selecting these criteria we considered several approaches. Fossey et al. ${ }^{3}$ outline clear, broad criteria which we adopted as a useful assessment framework. Additional criteria were included from three similar frameworks: the Critical Appraisal Skills Programme, ${ }^{14}$ Greenhalgh and Taylor ${ }^{8}$ and Popay et al. ${ }^{15}$ Seven criteria were drawn from these sources and are presented in Table 1. 


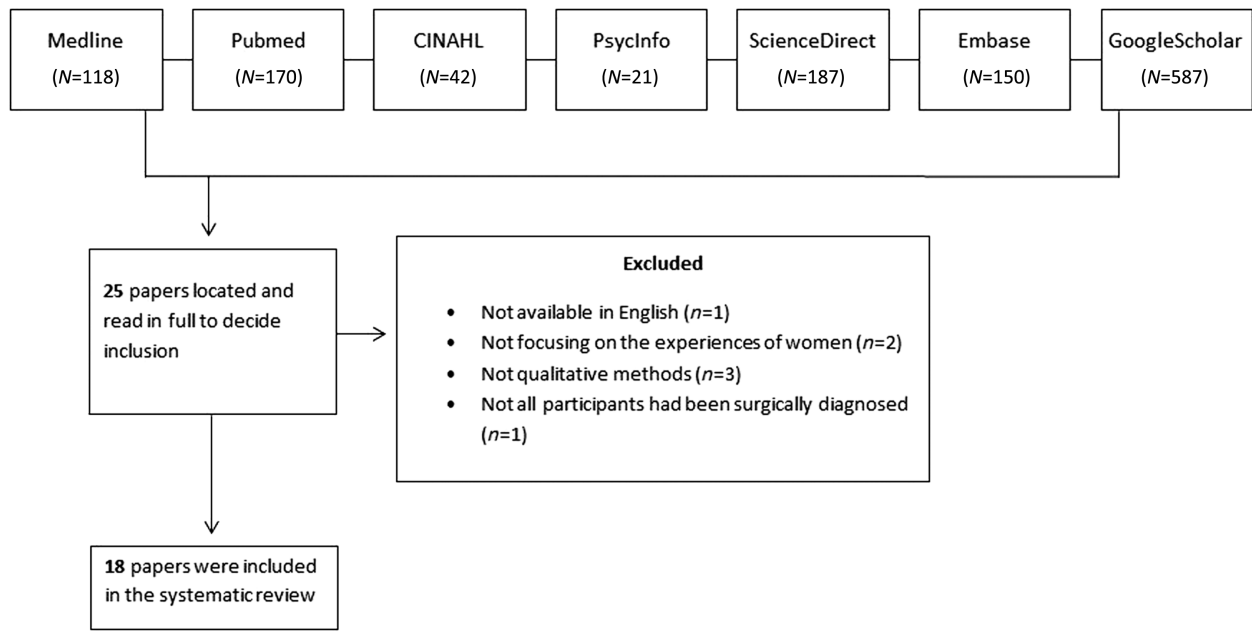

Figure 1 Flowchart presenting the number of articles retrieved, and included and excluded in this systematic review.

\section{Data analysis}

There are several methods available for synthesising results of qualitative research; few have been evaluated. ${ }^{16}$ Thematic analysis was employed for this review because it enables an organised, structured summary of themes. ${ }^{17}$ We used a data-driven method dependent on the themes identified within the papers rather than imposing a pre-existing coding frame, following the familiar six steps of thematic analysis. ${ }^{17}$

Papers were initially read when being considered for inclusion in the review. Selected papers were re-read and all themes and patterns noted. The identified themes were then systematically assessed and reorganised hierarchically with the aid of tables and concept maps. All components of the thematic scheme were evaluated against the data and reviewed to assess whether each constituted an individual

Table 1 Quality assessment criteria applied in the review

\begin{tabular}{|c|c|}
\hline Criteria & Source \\
\hline $\begin{array}{l}1 \text { Does the study make the research objective/ } \\
\mathrm{s} \text { clear? }\end{array}$ & Fossey et $a l^{13}$ \\
\hline $\begin{array}{l}2 \text { Is there evidence that a qualitative } \\
\text { approach is justified by the research } \\
\text { question? }\end{array}$ & $\begin{array}{l}\text { Critical Appraisal Skills } \\
\text { Programme }{ }^{14} \\
\text { Fossey et al. }{ }^{13} \\
\text { Greenhalgh and Taylor }^{8}\end{array}$ \\
\hline $\begin{array}{l}3 \text { Is the participant selection method } \\
\text { appropriate and adequate, and clearly } \\
\text { articulated? }\end{array}$ & Fossey et al. ${ }^{13}$ \\
\hline 4 Is the data collection method appropriate? & $\begin{array}{l}\text { Critical Appraisal Skills } \\
\text { Programme } e^{14} \\
\text { Fossey et al. }{ }^{13}\end{array}$ \\
\hline $\begin{array}{l}5 \text { Is the data analysis procedure adequate and } \\
\text { transparent? }\end{array}$ & Fossey et al. ${ }^{13}$ \\
\hline $\begin{array}{l}6 \text { Does the interpretation of the findings } \\
\text { reflect the perspective of those it claims to } \\
\text { represent? }\end{array}$ & $\begin{array}{l}\text { Fossey et al. }{ }^{13} \\
\text { Popay et al. }{ }^{15}\end{array}$ \\
\hline $\begin{array}{l}7 \text { Has the relationship between the researcher } \\
\text { and the participants been considered? }\end{array}$ & $\begin{array}{l}\text { Fossey et al. }{ }^{13} \\
\text { Critical Appraisal Skills } \\
\text { Programme }\end{array}$ \\
\hline
\end{tabular}

theme or should be combined with another component or eliminated. Subthemes potentially associated with more than one theme were allocated to the theme of best fit. The thematic scheme was then refined, with definitions and names established for each component. Finally, the results of this analysis were compiled using illustrative examples.

\section{RESULTS}

The search strategy yielded 18 papers for inclusion in the review (Table 2); these 18 papers reported on 11 studies. To avoid giving undue influence to studies described in multiple papers, themes are reported by the number of contributing studies, not the number of papers.

All studies were conducted in five high-income countries: the UK $(n=7)$, Australia $(n=7)$, New Zealand $(n=2)$, Canada $(n=1)$ and France $(n=1)$. Participant numbers ranged from 15 to 61 women and typically included women aged between 20 and 50 years, most of whom were recruited from specialised treatment clinics or support organisations. Few papers reported further demographic information, with those which did describing a predominantly Caucasian, 'middle class' sample.

\section{Quality assessment}

Overall, most studies were assessed as being of high quality. Some scored poorly on data analysis because of vague descriptions of data exploration methods, poor explanation of how themes were derived, and the use of inappropriate methods that bordered on a quantitative approach. Participant involvement in ensuring the accuracy of the researchers' interpretations was not always evident, and few studies related their findings to existing theory or bodies of knowledge. Specific studies where the quality criteria set out in Table 1 were not met were Ballard et al. ${ }^{18}$ Cox et $a l^{20}$ and Markovic et $a l .^{31}$ (Criterion 5) and 
Table 2 Summary of reviewed papers

\begin{tabular}{|c|c|c|c|c|}
\hline Paper & Aim & $\begin{array}{l}\text { Participants }(n) \\
\text { (age range in years) }\end{array}$ & Data collection & Analysis \\
\hline Ballard et al. ${ }^{18}$ & $\begin{array}{l}\text { To investigate the impact of delay in diagnosis of } \\
\text { endometriosis on women }\end{array}$ & $28 \quad(16-47)$ & Semi-structured interviews & Thematic \\
\hline Cox et al. ${ }^{19 \bullet}$ & $\begin{array}{l}\text { To examine women's experiences of endometriosis } \\
\text { and the lack of support for sufferers }\end{array}$ & $61 \quad(20-64)$ & Focus groups & Thematic \\
\hline Cox et al. ${ }^{20 \bullet}$ & $\begin{array}{l}\text { To report on women's experiences of endometriosis } \\
\text { in relation to the use of complementary therapies }\end{array}$ & $61 \quad(20-64)$ & Focus groups & Thematic \\
\hline $\begin{array}{l}\text { Denny and } \\
\text { Mann } 21-\end{array}$ & $\begin{array}{l}\text { To determine the impact of endometriosis-associated } \\
\text { dyspareunia on the lives and relationships of women }\end{array}$ & $30 \quad(19-44)$ & Semi-structured interviews & Thematic \\
\hline $\begin{array}{l}\text { Denny and } \\
\text { Mann22- }\end{array}$ & $\begin{array}{l}\text { To explore women's experiences of the primary care } \\
\text { setting }\end{array}$ & $30 \quad(19-44)$ & Semi-structured interviews & Thematic \\
\hline Denny ${ }^{23}$ & $\begin{array}{l}\text { To explore women's experiences of living with } \\
\text { endometriosis }\end{array}$ & $15 \quad(20-47)$ & Semi-structured interviews & $\begin{array}{l}\text { Thematic, } \\
\text { content }\end{array}$ \\
\hline Denny ${ }^{24}$ & $\begin{array}{l}\text { To explore women's experiences of living with the } \\
\text { pain of endometriosis and to examine delay in } \\
\text { diagnosis }\end{array}$ & $20 \quad(20-47)$ & In-depth interviews & Content \\
\hline Denny ${ }^{25}$ & $\begin{array}{l}\text { To explore women's experiences of living with } \\
\text { endometriosis }\end{array}$ & 30 (age not described) & $\begin{array}{l}\text { Semi-structured interviews, } \\
\text { diary-keeping }\end{array}$ & Thematic \\
\hline $\begin{array}{l}\text { Fauconnier } \\
\text { et al. }\end{array}$ & $\begin{array}{l}\text { To examine women's perceptions of symptoms of } \\
\text { endometriosis and to compare them with those of } \\
\text { physicians }\end{array}$ & $41 \quad(21-45)$ & 'In-depth' interview (10 minutes) & $\begin{array}{l}\text { Colaizzi's } \\
\text { method } \\
\text { (adaption) }\end{array}$ \\
\hline $\begin{array}{l}\text { Gilmour } \\
\text { et al. }{ }^{27 \star}\end{array}$ & $\begin{array}{l}\text { To explore the impact of symptomatic endometriosis } \\
\text { on women's social and working life }\end{array}$ & $18 \quad(16-45)$ & Semi-structured interviews & Thematic \\
\hline $\begin{array}{l}\text { Huntington and } \\
\text { Gilmour } \\
2{ }^{8 \star}\end{array}$ & $\begin{array}{l}\text { To explore women's perceptions of living with } \\
\text { endometriosis }\end{array}$ & $18 \quad(16-45)$ & Semi-structured interviews & Thematic \\
\hline Jones et al. ${ }^{29}$ & $\begin{array}{l}\text { To explore and describe the impact of endometriosis } \\
\text { upon quality of life }\end{array}$ & $24(21.5-44)$ & In-depth interviews & $\begin{array}{l}\text { Grounded } \\
\text { theory }\end{array}$ \\
\hline $\begin{array}{l}\text { Manderson } \\
\text { et al. }\end{array}$ & $\begin{array}{l}\text { To describe the factors that lead women with } \\
\text { endometriosis to initially seek medical advice }\end{array}$ & $40 \quad(20-78)$ & In-depth interviews & $\begin{array}{l}\text { Grounded } \\
\text { theory }\end{array}$ \\
\hline $\begin{array}{l}\text { Markovic } \\
\text { et al. }\end{array}$ & To describe women's experiences of endometriosis & $(20-78)$ & In-depth interviews & $\begin{array}{l}\text { Grounded } \\
\text { theory }\end{array}$ \\
\hline Seear $^{32 \square}$ & $\begin{array}{l}\text { To capture women with endometriosis' reluctance to } \\
\text { disclose menstrual irregularities }\end{array}$ & $20 \quad(24-55)$ & Semi-structured interviews & Interactive \\
\hline Seear $^{33} \square$ & $\begin{array}{l}\text { To explore non-compliance with health care advice } \\
\text { from the perspective of women with endometriosis }\end{array}$ & $20 \quad(20-55)$ & Semi-structured interviews & Interactive \\
\hline Seear ${ }^{34 \square}$ & $\begin{array}{l}\text { To explore how women with endometriosis become } \\
\text { experts in their own care }\end{array}$ & $20 \quad(20-55)$ & Semi-structured interviews & Interactive \\
\hline Whelan ${ }^{35}$ & $\begin{array}{l}\text { To demonstrate why and how experience becomes } \\
\text { crucial to endometriosis patient community members }\end{array}$ & 24 (age not described) & $\begin{array}{l}\text { Focus group meetings, } \\
\text { open-ended questionnaire } \\
\text { conducted via email }\end{array}$ & $\begin{array}{l}\text { Grounded } \\
\text { theory }\end{array}$ \\
\hline
\end{tabular}

$\overline{\bullet=\star \square}$ OSymbols indicate data generated by the same study.

Fauconnier et al. ${ }^{26}$ (Criterion 4). However, no study was assessed as being too poor for inclusion in the synthesis of results.

\section{Thematic analysis}

Themes were selected if they met at least one of these two criteria: (1) represented a patterned response or meaning across the reviewed paper; or (2) captured something significant relative to the experience of endometriosis. ${ }^{17}$ Four primary themes were identified as characterising the data in this review: Life, Symptoms, Medical Experience, and Self.

\section{Life}

Across the reviewed studies, it was clear that endometriosis affected all areas of a woman's life, most notably sex life, social life and work life.
Sex life

Papers from five studies reported women's experiences of endometriosis-related dyspareunia (painful sexual intercourse) and its effect on intimate relationships. $^{21} 23 \quad 242628 \quad 32$ Women reported experiencing pain during intercourse and for hours or days after. Descriptors of this pain included "sharp", "deep", "sore", "agony" and "burning". One woman explained it as being:

"As if your flesh was laid bare, a kind of electric feeling [...] as if, I don't know, not exactly a burn but the nerves laid bare." 26

Women employed various strategies to manage pain during and after intercourse, including changing positions, enduring the pain, discontinuing, or avoiding 
sexual activity altogether. Only Denny and Mann ${ }^{21}$ included mention of coping strategies such as exploring non-penetrative sexual activity or alternative ways to be intimate; these were typically reported by 'older' women (the reviewers do not define what they mean by older; the upper age bracket of participants for this study was 44 years).

These five studies revealed the adverse impact of painful intercourse on women's intimate relationship, such as "tension", "friction" or "strain". Partners were reported as feeling "rejected", while women felt "guilt", "inadequacy" or that they were a "bad person" for being unable to meet their partner's or society's expectation for sexual activity. Participants in three studies reported that the ramifications of pain associated with intercourse had contributed to relationship break-ups. ${ }^{21} 232428$

Women in one study ${ }^{23} 24$ said they would not volunteer to doctors that they experienced painful sexual intercourse because it was personal and embarrassing information. The one woman who reported consulting her doctor was told that her pain "might be a psychological problem" and that she was probably "anxious". Few women said that their general practitioner (GP) had asked them about pain associated with intercourse.

Social life

Papers from three studies included women's comments on the effect of endometriosis on their social lives. ${ }^{23} 2729$ Women's participation in social activities could be significantly reduced by the direct effects of debilitating symptoms, the need to be near a lavatory (because of vomiting, and gastrointestinal and bladder problems), and worry about experiencing symptoms in public. Women spoke of "changing their plans" or "missing out", feeling as though they had "no social life at all".

\section{Work life}

Papers from five studies highlighted women's work lives as being severely affected by endometriosis, with some women taking numerous sick days and others being unable to fulfil their job requirements. ${ }^{23} 25$ 27-29 3233 Women spoke of concealing their condition from their male colleagues because of the perceived taboo against discussing reproductive matters in the presence of men. Concealment from colleagues also served to avoid accusations such as using endometriosis as an excuse to "get out of things" or expectations that all women should "put up with" reproductive system pain.

Papers from two studies found that women could experience significant disruption to education and careers. $^{23} 2728$ Fatigue, severe pain and the side effects of strong painkillers (e.g. drowsiness, nausea) were associated with inability to work. While some women reported supportive and accommodating employers, the majority were not given suitable working conditions and were therefore forced into part-time work or to cease employment.

Symptoms

Despite the many symptoms associated with endometriosis (such as nausea, diarrhoea and fatigue), the reviewed papers tended to deal only with women's experiences of pain (including during intercourse) and infertility.

Pain

Papers from five studies reported women's descriptions of pain and, to varying extents, the impact of pain on women's lives. ${ }^{23-26} 2829$ Intensity was central to these descriptions, with women describing pain as "crippling”, "contractions", "horrific", "sharp", "stabbing" and "overwhelmed every other sense in your body". Duration was also important: "nags all day long", "never, ever went away" and "getting worse with time". According to papers from three studies, location of pain was significant and diverse, within as well as between women, occurring in the pelvis, bladder, bowel, back, gastrointestinal tract and joints, as well as in association with sexual intercourse. ${ }^{26} 2829$

Three studies found that women experienced pain as controlling their lives. ${ }^{25} 2829$ While some women could predict their pain because it was associated with their menstrual cycle, others experienced continuous or random pain that inhibited their economic and social participation, even to the extent that "life is permanently on hold". 25

Women in two studies reported that health care providers rarely asked about the qualitative nature of their pain, ${ }^{23-25}$ with one woman saying:

"And I'd want someone to say 'Well, what type of pain is it? '... They just seemed to be writing a lot, and not really looking at me or taking any notice of me.",23 24

Women considered pain's duration and quality (a rich description, such as how it feels, change according to context, its effect on daily tasks) to be important, whereas they reported health professionals as emphasising the site and level of pain (using numeric scales).

Infertility

Two studies found fertility-related matters to be important to women. ${ }^{19}{ }^{29}$ Jones et al. ${ }^{29}$ reported that some women felt worried and/or depressed about either their diagnosed infertility or the possibility of infertility:

"That was probably one of the worst things, the desperation to have a child and that it took 5 years to get pregnant. That was probably the worst thing for me really." 29

Some women said that their long-term relationships had "suffered" from the "strain" of fertility problems. ${ }^{29}$ 
Although one woman described herself as not feeling like "a complete woman" because of her inability to conceive through sexual intercourse, ${ }^{29}$ other women were reported as resenting being judged as not "real women" because of their infertility. ${ }^{19}$

A further two studies included minor mention of fertility-related matters. ${ }^{25} 31$ One paper reported women commenting on fertility only when asked how they viewed their futures; ${ }^{25}$ another reported infertility only in relation to a need for more advice on conception and fertility. ${ }^{31}$

\section{Medical experience}

Women's experiences of medical care for endometriosis, including diagnosis delay, treatments, and experience with care providers, were reported in many of the reviewed papers.

\section{Diagnosis delay}

Delay in diagnosing endometriosis was the most commonly reported theme, reported in papers from 10 studies. ${ }^{18} 19$ 22-25 28-32 3435 Diagnosis delay occurred more in the primary care setting than within secondary care, with reasons categorised as associated with either the woman or health professionals.

It was reported in papers from two studies that some women delayed seeking help for their symptoms because they believed all women had painful periods. ${ }^{18} 30^{31}$ Five studies found that when women did reveal their symptoms to a family member, friend, teacher or colleague, their experiences were typically normalised as being what all women must endure. $^{19} 22 \quad 25$ 30-32 Symptoms could thus be dismissed even in families with a history of gynaecological problems.

Women were reported as most commonly attributing diagnosis delays to health professionals. Seven studies found GPs, in common with families and friends, often normalised symptoms as no more than women should expect: ${ }^{18} 22-2428293135$

"The doctor told me that the problem nowadays is that because women take the Pill, they don't know what a real period pain is. It's just the most dismissive, unhelpful comment ever!" 18

This occurred even when there was a family history of endometriosis. ${ }^{31}$

Two studies included a woman who found that her concerns were recognised and accurately diagnosed only when they were characterised as being fertility-related. ${ }^{31}{ }^{32}$ Markovic et al. ${ }^{31}$ described a woman whose reports of menstrual pain as a young, single woman were dismissed for years until she consulted a doctor as a married professional presenting with infertility. Seear ${ }^{32}$ included the experiences of a woman who, upon experiencing heavy menstrual bleeding, consulted a doctor out of concern that her plans to become pregnant would be impeded. The authors of both papers speculated that when women framed their problems as pertaining to fertility, their doctors took their concerns seriously instead of dismissing them as 'mere' menstrual pain.

Women were found in four studies to have assessed their doctors as preferring to diagnose irritable bowel syndrome or psychological problems rather than identify a gynaecological cause. ${ }^{22} 242829$ Women were reported as saying that health professionals with this attitude took various courses of action that further delayed diagnosis, including suppressing symptoms with the oral contraceptive pill rather than arranging investigations, ordering scans that cannot detect endometriosis, and advising pregnancy. ${ }^{18} 1923-2529$ Some women had to persuade their GP to refer them to a gynaecologist: ${ }^{19} 22$

"I probably went [to the GP] on and off for quite a while before they sent me. He was always very reluctant to pass me on [to a gynaecologist] which has been a lot of wasted time."22

Women's reactions to a diagnosis of endometriosis were reported in papers from seven studies. ${ }^{18} 22242528313435$ Most women said they felt vindicated after having their symptoms dismissed or disbelieved by relatives, friends, colleagues and health professionals. Some appreciated seeing physical evidence of their 'invisible disease' in photographs and videos following surgery. ${ }^{24} 25$ Diagnosis validated women's experiences and provided a medical term with which they could explain their symptoms to others: "It's not all in my head, it's got a name". ${ }^{28}$

Feelings of vindication and relief could give way to shock at being diagnosed with an incurable chronic disease, and women could feel anger at those who had not taken their problems seriously.

\section{Treatments}

Women's experiences with treatments, including trialling various surgical, medical and alternative approaches, were reported in papers from seven studies. $^{20} 23 \quad 25272931 \quad 33$ Women were found to prefer surgical over medical treatments because the former were perceived to be associated with increased symptom relief and fewer side effects. ${ }^{24} 25$ Many women worried about the short- and long-term side effects of various treatments, ${ }^{29}$ particularly medical options:

"You can look at your life in the hands of doctors and these drugs, but none of it's that proven and it's all got pretty horrible side effects." 23

Only one paper included findings about women's experience with decision-making and treatment options, ${ }^{20}$ reporting that women felt liberated when making independent decisions about their treatment, particularly surgery, and upon realising that it was their choice, not their doctor's. Many women felt 
despair and anger over the constant disappointment of treatments that provided little or no relief. ${ }^{27} 29$

Women were reported in papers from six studies to have sought alternative and complementary medical treatment or to have engaged in diverse selfmanagement practices including heat, TENS (transcutaneous electrical nerve stimulation), diet changes and

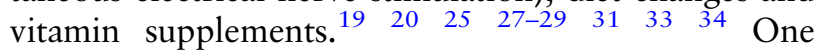
study ${ }^{33}$ found that women could be prompted by health professionals to engage in these selfmanagement practices. Whilst some women said that such practices relieved symptoms and "empowered" them, others said that it increased the burden of endometriosis by requiring them to manage their own care:

"I wish I could hand over my care to someone else and it would be like you sort out my health issues, you make me better in some way and I don't feel that there is anyone I can hand it to, but that I have to do all of that. ${ }^{34}$

Experience with health professionals

Papers from eight studies reported women's postdiagnosis experiences with care providers, where women frequently claimed that doctors lacked knowledge of endometriosis which limited the provision of adequate support, care and information. ${ }^{19} 22 \quad 2527-$ $293133 \quad 35$ Some women said that, as a result, they placed little trust in doctors. Doctors' lack of knowledge could be represented as ignorance of what it is like to live with endometriosis, ${ }^{25}$ leaving women feeling obliged to educate doctors about the disease. $^{19} 35$ Denny and Mann ${ }^{22}$ reported, however, that women could perceive doctors as compensating for their limited knowledge of endometriosis by listening to the woman, treating her sympathetically, and referring her appropriately.

Women in four studies were reported as having health care professionals recommend "medical myths" such as marriage and pregnancy or hysterectomy to treat their endometriosis. ${ }^{28} 293133$ Women were upset and offended by this advice, particularly when pregnancy was impossible or inadvisable because of their age, sexuality, infertility or financial limitations:

\section{"When I first went to see the gynaecologist, he said, go out and have a child. You're telling an 18-year-old girl who's single to go out and have a baby, come on, what do you expect me to do?"31}

Doctors' lack of knowledge and insensitive communication discouraged some women from consulting them, even for symptoms such as severe abdominal pain and rectal bleeding. ${ }^{19} 2533$

\section{Self}

Aside from their experience of physical symptoms, women were rarely reported as speaking of the direct impact of endometriosis on themselves. It was unclear whether this was a result of women not being asked about this topic or women choosing not to speak about it. Exceptions tended to describe a woman's acquisition of information and her increasing knowledge, her emotional health, and her thoughts about the future.

Information and knowledge

Papers from six studies included women's experiences of information-seeking and developing knowledge about endometriosis. ${ }^{19} 20242728313435$ Whelan's $^{35}$ analysis led her to conclude that, to make sense of their own and others' experiences and to evaluate the validity of clinicians' statements and medical claims, women recognised a hierarchy of knowledge with their own and other women's experience at the top, research in the middle, and clinician opinion at the bottom. Women used all three varieties of knowledge for various purposes, including adopting the medical diagnosis as a means of entry into the exclusive world of endometriosis patients, but they consistently privileged experiential knowledge as more reliable. ${ }^{35}$

Women reported using diverse sources of information associated with the three types of knowledge, with the most popular being endometriosis support groups, the Internet, other women and books. ${ }^{27} 28313435$ Medical publications were used less often. ${ }^{35}$

Women identified both beneficial and adverse effects of seeking information and gaining knowledge. Papers from two studies reported that women felt that their detailed knowledge of endometriosis gave them a sense of control and power over both the disease itself and health professionals. ${ }^{19} 2035$ However, some women felt burdened by constant information-seeking and wanted someone else - usually their doctor - to take responsibility for seeking and providing information. ${ }^{34} 35$

\section{Emotional well-being}

Women in five studies reported adverse effects of endometriosis on their emotional well-being, often feeling "weary", "miserable", "angry" and "depressed" as a result of the symptoms and their ramifications. ${ }^{19} 2026272935$ Evidence presented in these papers indicated that women's sense of wellbeing was reduced not only by their symptoms but by the ways in which others (health professionals, partners, family, friends and colleagues) related to them and their condition. Particularly harmful were those health care professionals who defined the symptoms as representing poor mental health, often crudely labelling women as "crazy" or "depressed".

\section{The future}

Women's perceptions of the future were reported in papers from three studies, with "worry" a consistent theme. ${ }^{19} 202325$ The most important concerns were symptoms returning or worsening, future fertility problems, ability to cope with the disease in the long 
term, and whether their daughters would experience endometriosis and encounter the same difficulties in receiving treatment:

"I just don't know how I'm going to put up with this for the rest of my life. At the moment I feel that I've got, I suppose, a sentence over me of pain. ${ }^{.23}$

It was found in one study that many women engage in goal-setting, with most aiming to be free of pain without using drugs. ${ }^{19}{ }^{20}$ Younger women and women who were pain-free at the time of interview were, according to two studies, typically more optimistic about their future. ${ }^{23} 25$

\section{DISCUSSION}

This review identified 18 studies that examined women's experiences of endometriosis using qualitative research methods. Overall, this body of literature was assessed to be of high quality and as reporting on a variety of experiences. However, the participant samples lacked diversity, with little inclusion of adolescent and post-menopausal women, women from low socioeconomic backgrounds, and women who do not identify as Caucasian or heterosexual, and including only women from either specialised treatment clinics or support groups.

There were some themes, such as the impact of reduced social participation on perceived support and emotional well-being, that, given the results reported in the literature not eligible for this review, we expected to be reported but were not. It was unclear whether this is because it was not important to the women interviewed, because the research approach did not invite such accounts, or because the authors had chosen not to include them in their published work. With these limitations in mind, the themes identified in this review represent the reported experiences and interpretations of participants in the included studies, many of which are supported by the literature beyond the inclusion criteria of this review.

Consistent with survey studies that demonstrate a large percentage of women with endometriosis experience painful sexual intercourse and associated reduced quality of life, ${ }^{36-38}$ this review of qualitative research found that women experience painful sexual intercourse and explored the impact of this on themselves and their relationship. Previous research has also quantified the impact of endometriosis on work life. For example, Simoens et al. ${ }^{39}$ estimated that a woman with endometriosis living in Europe or America experiences an average annual loss of productivity cost of $€ 6298$, while Fourquet et al. ${ }^{37}$ reported that women lose approximately one working day per week when their symptoms are "prevalent". The current review advances knowledge by identifying some of the factors that contribute to these results, such as a lack of flexibility in the workplace to accommodate the needs of women with endometriosis.
Surveys consistently find a correlation between endometriosis and poor mental health. ${ }^{3640}$ However, a correlation cannot reveal the direction or meaning of the relationship. This review found that women attributed their emotional difficulties to the ramifications of living with a complex chronic condition and denied that such difficulties preceded endometriosis. Nevertheless, women encountered doctors who diagnosed poor mental health as causing their symptoms. The tendency among health professionals to 'psychologise' health conditions experienced by women that medicine cannot explain has a long, well-documented history. ${ }^{41}$ As scientific advances are made and women's sociopolitical context is recognised, more accurate explanations emerge.

Women's descriptions of endometriosis-associated pain and delay in diagnosis provide further insight into the results of previous research using quantitative methods. Sepulcri et $a l^{40}$ found an association between increased pain and decreased quality of life, with women reporting an average score of 5 on a visual analogue scale (VAS) where response options range from 1 to 10 (the authors do not state what these scale anchors signify). While the attempt to quantify a subjective experience is understandable, it is not clear what a score of 5 means to women, nor can we comprehend from it the impact of this pain level on women's lives. Further, it has been suggested that such scales are not reflective of the language used by women with chronic pelvic pain nor do they emphasise the same components of pain that women do. ${ }^{42}$ The qualitative research synthesised in this review included in-depth exploration of women's accounts of pain and their recommendations for how health professionals should inquire about pain. Similarly, the useful quantification of average patient delay (time between onset of symptoms and first doctor visit) as 2.1 years and average doctor delay (time between first doctor visit and diagnosis) as 3.4 years $^{36}$ has been illuminated by the current synthesis of qualitative research: women attribute diagnosis delay to their own beliefs and behaviours and those of their family and friends, but even more to the beliefs and attitudes of health professionals.

In contrast to the illumination of women's experience of endometriosis presented in the foregoing examples, there are aspects of the experience yet to be more fully investigated. For example, it is often claimed that $30 \%$ of women with endometriosis experience infertility, although it is difficult to find recent data; a common citation is a paper more than 70 years old. ${ }^{43}$ Nevertheless, very few reviewed studies reported women giving accounts of actual or anticipated infertility. Papers that did report women's experiences of, or thoughts on, infertility presented little in-depth analysis of its effects on women's identity, intimate relationships, or expectations for the future. The relationship between painful sexual 
intercourse and achieving fertility goals was also not explored. Surveys have found that women's social participation can be inhibited by endometriosis. ${ }^{37} 39$ Although results of qualitative research are consistent with the surveys, their lack of in-depth analysis makes it difficult to determine what this means to women for the availability of support and their emotional well-being. These gaps in knowledge provide important avenues for further research, including women's experiences of endometriosis-associated infertility and inhibited social participation. This research should ensure diversity among participants in terms of age, socioeconomic status, cultural and linguistic background, and sexual identity.

\section{CONCLUSIONS}

The results of this review have implications for health care. Although qualitative research does not assume that there is an 'essence' of an experience to be captured and therefore generalised, it builds a picture by accumulating knowledge of women's perspectives. ${ }^{12}$ The experiences presented in this review may therefore be recognised by, and apply to, a variety of women with endometriosis and those who care for them. It is with this understanding that we suggest the following implications for health care.

It is evident that health professionals would benefit from improved pre-service and in-service education about, and knowledge of, endometriosis in order to reduce diagnostic delay and enhance women's experience of care. Women may find help-seeking to be a less stressful experience if health professionals understood pain in all its aspects and ramifications, asking about the nature of the pain (duration, quality, site, level) and its effects on their life. It may also be appropriate for health professionals to assist women with the impact of endometriosis on their sex lives by sensitively broaching this topic and assessing women's willingness to discuss it (Box 1). ${ }^{44}$

Considering the chronic, recurring nature of endometriosis, it is desirable to offer women a long-term management plan designed to ease worry about their future, to enable them to feel supported, and to ensure long-term access to appropriate health care. Health professionals can also be a valuable resource in assisting women to communicate their needs arising from endometriosis, such as providing a letter to employers explaining endometriosis and suggesting simple measures to assist the woman to meet her job requirements, or enabling a woman to invite partners or family members to join her at consultations, should she wish this.

As this review has confirmed, endometriosis affects all areas of a women's life. The review has also identified gaps in the current evidence base and presented implications for current health care practice. Further research is needed to a gain a comprehensive understanding of endometriosis as experienced by diverse
Box 1 Useful techniques for health professionals to gauge the impact of endometriosis on a woman's life

- Inquire about areas of life known to be adversely affected by endometriosis (e.g. un/paid employment, education, intimate relationship and/or sex life, social life).

- Use open-ended questions when history taking (e.g. Please tell me about...? How has that affected...?).

- Do not assume that all women with endometriosis are adversely affected.

- Offer your services to assist others in understanding endometriosis and the impact it has on a woman (e.g. providing a letter to employers and inviting a woman's partner, relative or friend to join her at consultations).

- If you have little knowledge of endometriosis be honest about this with the woman, treat her sympathetically and refer her appropriately (or ask a more knowledgeable colleague to assist you).

groups of women, thus enabling the development, implementation and evaluation of interventions that may reduce the burden of this enigmatic condition.

Competing interests None.

Ethics approval Ethics approval was not required as this is a systematic review; no new research with human subjects was conducted.

Provenance and peer review Not commissioned; externally peer reviewed.

\section{REFERENCES}

1 Viganò P, Parazzini F, Somigliana E, et al. Endometriosis: epidemiology and aetiological factors. Best Pract Res Clin Obstet Gynaecol 2004;18:177-200.

2 Giudice LC. Endometriosis. N Engl J Med 2010;362:2389-2398.

3 Burney RO, Giudice LC. Pathogenesis and pathophysiology of endometriosis. Fertil Steril 2012;98:511-519.

4 Vercellini P, Fedele L, Aimi G, et al. Association between endometriosis stage, lesion type, patient characteristics and severity of pelvic pain symptoms: a multivariate analysis of over 1000 patients. Hum Reprod 2007;22:266-271.

5 Johnson NP, Hummelshoj L. Consensus on current management of endometriosis. Hum Reprod 2013;28:1552-1568.

6 Denny E, Khan KS. Systematic reviews of qualitative evidence: what are the experiences of women with endometriosis? J Obstet Gynaecol 2006;26:501-506.

7 Britten N. Qualitative research on health communication: what can it contribute? Patient Educ Couns 2011;82:384-388.

8 Greenhalgh T, Taylor R. How to read a paper: papers that go beyond numbers (qualitative research). BMJ 1997;315: $740-743$.

9 Kitto SC, Chesters J, Grbich C. Quality in qualitative research. Med J Aust 2008;188:243-246.

10 Dixon-Woods M, Bonas S, Booth A, et al. How can systematic reviews incorporate qualitative research? A critical perspective. Qual Res 2006;6:27-44. 
11 Culley L, Law C, Hudson N, et al. The social and psychological impact of endometriosis on women's lives: a critical narrative review. Hum Reprod 2013;19:625-639.

12 Liamputtong P. Qualitative Research Methods (3rd edn). Melbourne, Australia: Oxford University Press, 2009.

13 Fossey E, Harvey C, Mcdermott F, et al. Understanding and evaluating qualitative research. Aust N Z J Psychiatry 2002;36:717-732.

14 Critical Appraisal Skills Programme. 10 questions to help you make sense of qualitative research: Critical Appraisal Skills Programme, 2010. http:/www.casp-uk.net/wp-content/uploads/ 2011/11/CASP_Qualitative_Appraisal_Checklist_14oct10.pdf [accessed 6 May 2013].

15 Popay J, Rogers A, Williams G. Rationale and standards for the systematic review of qualitative literature in health services research. Qual Health Res 1998;8:341-351.

16 Dixon-Woods M, Agarwal S, Jones D, et al. Synthesising qualitative and quantitative evidence: a review of possible methods. J Health Serv Res Policy 2005;10:45B-53B.

17 Braun V, Clarke V. Using thematic analysis in psychology. Qual Res Psych 2006;3:77-101.

18 Ballard K, Lowton K, Wright J. What's the delay? A qualitative study of women's experiences of reaching a diagnosis of endometriosis. Fertil Steril 2006;86:1296-1301.

19 Cox H, Henderson L, Andersen N, et al. Focus group study of endometriosis: struggle, loss and the medical merry-go-round. Int J Nurs Pract 2003;9:2-9.

20 Cox H, Henderson L, Wood R, et al. Learning to take charge: women's experiences of living with endometriosis. Complement Ther Nurs Midwifery 2003;9:62-68.

21 Denny E, Mann CH. Endometriosis-associated dyspareunia: the impact on women's lives. J Fam Plann Reprod Health Care 2007;33:189-193.

22 Denny E, Mann $\mathrm{CH}$. Endometriosis and the primary care consultation. Eur J Obstet Gyne Reprod Biol 2008;139:111-115.

23 Denny E. Women's experiences of endometriosis. J Adv Nurs 2004;46:641-648.

24 Denny E. 'You are one of the unlucky ones': delay in the diagnosis of endometriosis. Divers Health Soc C 2004;1:39-44.

25 Denny E. "I never know from one day to another how I will feel": pain and uncertainty in women with endometriosis. Qual Health Res 2009;19:985-995.

26 Fauconnier A, Staraci S, Huchon C, et al. Comparison of patient- and physician-based descriptions of symptoms of endometriosis: a qualitative study. Hum Reprod 2013;28:1-9.

27 Gilmour JA, Huntington A, Wilson HV. The impact of endometriosis on work and social participation. Int J Nurs Pract 2008;14:443-448.
28 Huntington A, Gilmour JA. A life shaped by pain: women and endometriosis. J Clin Nurs 2005;14:1124-1132.

29 Jones G, Jenkinson C, Kennedy S. The impact of endometriosis upon quality of life: a qualitative analysis. J Psychosom Obstet Gynaecol 2004;25:123-133.

30 Manderson L, Warren N, Markovic M. Circuit breaking: pathways of treatment seeking for women with endometriosis in Australia. Qual Health Res 2008;18:522-534.

31 Markovic M, Manderson L, Warren N. Endurance and contest: women's narratives of endometriosis. Health (NY) 2008;12:349-367.

32 Seear K. The etiquette of endometriosis: stigmatisation, menstrual concealment and the diagnostic delay. Soc Sci Med 2009;69:1220-1227.

33 Seear K. 'Nobody really knows what it is or how to treat it': why women with endometriosis do not comply with healthcare advice. Health Risk Soc 2009;11:367-385.

34 Seear K. The third shift: health, work and expertise among women with endometriosis. Health Sociol Rev 2009;18:194-206.

35 Whelan E. 'No one agrees except for those of us who have it': endometriosis patients as an epistemological community. Sociol Health Illn 2007;29:957-982.

36 De Graaff AA, D'Hooghe TM, Dunselman GA, et al. The significant effect of endometriosis on physical, mental and social wellbeing: results from an international cross-sectional survey. Hum Reprod 2013;28:2677-2685.

37 Fourquet J, Báez L, Figueroa M, et al. Quantification of the impact of endometriosis symptoms on health-related quality of life and work productivity. Fertil Steril 2011;96:107-112.

38 Nnoaham KE, Hummelshoj L, Webster P, et al. Impact of endometriosis on quality of life and work productivity: a multicenter study across ten countries. Fertil Steril 2011;96:366.e8-373.e8.

39 Simoens S, Dunselman G, Dirksen C, et al. The burden of endometriosis: costs and quality of life of women with endometriosis and treated in referral centres. Hum Reprod 2012;27:1292-1299.

40 Sepulcri Rde P, do Amaral VF. Depressive symptoms, anxiety, and quality of life in women with pelvic endometriosis. Eur J Obstet Gyne Reprod Bio 2009;142:53-56.

41 Ussher JM. The Madness of Women: Myth and Experience. Hove, UK: Routledge, 2011.

42 Grace VM, MacBride-Stewart S. "How to say it": women's descriptions of pelvic pain. Women Health 2008;46:81-98.

43 Counsellor VS. Endometriosis. A clinical and surgical review. Am J Obstet Gynecol 1938;36:877.

44 Hummelshoj L, De Graaff A, Dunselman G, et al. Let's talk about sex and endometriosis. J Fam Plann Reprod Health Care 2014;40:8-10. 